\title{
Escepticismo, materialismo y clandestinidad. Los primeros escritos de Diderot
}

Esteban Ponce*

Resumen: En este trabajo abordamos la relación entre escepticismo, materialismo y clandestinidad en los primeros escritos de Denis Diderot. A partir del estudio de las referencias al escepticismo encontradas en su traducción de An Inquiry Concerning Virtue or Merit de Shaftesbury y analizando las posiciones sostenidas posteriormente en dos obras de su propia autoría -Pensamientos filosóficos (1746) y El paseo del escéptico (1747)-, intentamos mostrar: a) qué significado tiene el escepticismo en tanto actitud filosófica en la obra del joven Diderot, y b) cómo se configuró la transformación de mitad de siglo en el movimiento ilustrado y qué papel cumplió nuestro autor en la misma.

Palabras clave: Diderot; escepticismo, materialismo, clandestinidad.

Abstract: In this paper, we study the connections between skepticism, materialism and clandestinity in Denis Diderot' first writings. Leaning on the references found in his translation of Shaftesbury's An Inquiry Concerning Virtue or Merit in the first place and, secondly, analyzing what Diderot says as an author in two of his works Philosophical Thoughts (1746) and The Skeptic's Walk (1747) - we try to show: a) what's the meaning of skepticism as a philosophical attitude in young Diderot's writings; b) how transformation at the Enlightenment movement in the second half of the Eighteenth Century was configured, and what was Diderot's role in that transformation.

Keywords: Diderot, Scepticism, Materialism, Clandestinity.

* Doctor en Filosofía por la Universidad de Buenos Aires (UBA). DocenteInvestigador de la Universidad Nacional del Litoral (UNL). Ha publicado una serie de trabajos relativos a la Ilustración, especialmente sobre el pensamiento de Denis Diderot y l'Encyclopédie. Actualmente realiza estudios posdoctorales como Becario del Consejo Nacional de Investigaciones Científicas y Técnicas (CONICET). Dirección electrónica: estebanponce@hotmail.com 


\subsection{Introducción.}

Escepticismo, materialismo y clandestinidad son términos que encontramos, por lo general, ligados a los textos de difusión de ideas antirreligiosas de principios del siglo XVIII. Es cierto que escepticismo y materialismo son posiciones filosóficas cuyo origen puede remontarse hasta la antigüedad, pero el modo en que se relacionan y el vínculo que tuvieron con la práctica de difusión clandestina representan una nueva configuración en la historia de la cultura. La circulación de esta literatura, cuyos secretos estaban destinados a quienes habitaban la invisible y cosmopolita República de las Letras, se realizaba a través de textos manuscritos (y de sus respectivas copias, no siempre del todo fieles a los originales), o bien en ediciones de unos pocos ejemplares. Respecto de este último modo, como ha mostrado Olivier Bloch, la divulgación de las ideas requería de un cuidadoso diseño que pusiera a los autores a salvo de la censura y la persecución de la ortodoxia oficial. ${ }^{1}$ Por ejemplo, se ocultaba la relación entre el escrito y su autor a través de una serie de estrategias editoriales como el anonimato, la pseudonimia, las falsas atribuciones y el camuflaje de los datos sobre el origen de publicación y las fechas de redacción.

El estudio de la literatura clandestina de la Ilustración, que ha recibido un notable impulso en las últimas décadas, ${ }^{2}$ puso de manifiesto que puede establecerse una diferencia entre los autores de principios del siglo XVIII herederos del libertinismo erudito del siglo precedente- y los autores que comenzaron a escribir hacia mediados de ese siglo. ${ }^{3}$ No se trata, por supuesto,

1 Bloch, O., Matière à histoire, Paris, Vrin, 1997, pp. 225-283.

$2 \mathrm{Al}$ respecto, ver: Canziani, G. (ed.), Filosofia e religione nella letteratura clandestina. Secoli XVII e XVIII, Milano, FrancoAngeli, 1994; Paganini, Benítez y Dybikowski (eds.), Scepticisme, Clandestinité et Libre Pensée, Paris, Honoré Champion, 2002; Paganinni, G., Les philosophies clandestines à l'âge classique, Paris, PUF, 2005. Ver, asimismo, la revista La lettre clandestine (1992-), dedicada especialmente a estos temas.

${ }^{3}$ Cfr. Dieckmann, H., "Themes and Structure of the Enlightenment", en Dieckmann, H. et al., Essays in Comparative Literature, St. Louis, Washington University Press, 1961, pp. 41-72; Rétat, P., Le Dictionnaire de Bayle et la lutte philosophique au XVIIIe. siècle, Paris, Les Belles Lettres, 1971; Israel, J. Radical Enlightenment. Philosophy and the Making of 
de una distinción clara y precisa; es, más bien, una transformación gradual que se va dando en el seno del movimiento ilustrado y que repercute en el modo en que los pensadores de la segunda mitad concibieron la función del filósofo y su tarea en la difusión del saber.

En este trabajo buscaremos mostrar cómo se opera esta transformación en las primeras obras de Diderot, prestando especial atención a tres cuestiones: la valoración del escepticismo en sus diversas aplicaciones, la recepción de las ideas de la Ilustración temprana y la renovación del ideal de philosophe. Para ello, será preciso comenzar nuestro análisis teniendo como referencia algunos pasajes de dos textos - la traducción de An Inquiry Concerning Virtue or Merit de Shaftesbury 4 y los Pensamientos filosóficos- en los que se consideran las diferentes maneras de entender el escepticismo; luego, el estudio de la obra El paseo del escéptico nos permitirá reflexionar sobre la recepción de las ideas de las distintas corrientes del movimiento ilustrado en Diderot, como así también sobre el rol que éste cumplió en el proceso de transformación de mitad de siglo. Esperamos con ello mostrar, a) que Diderot conocía muy bien el panorama de la situación de la filosofía en la que hace su aparición y que era conciente de ese proceso histórico de transformación que afectaba tanto al modo de hacer filosofía como a la manera de concebir su función social; b) que l'Encyclopédie puede ser entendida como el fruto de esta nueva representación del ideal de filósofo, y que, por eso mismo, Diderot debe ser considerado como uno de los protagonistas clave del giro que se produjo hacia mediados del Siglo de la Luces.

Modernity, 1650-1750, Oxford, Oxford University Press, 2001; y Enlightenment contested. Philosophy, Modernity, and the Emanicipation of Man, 1670-1752, Oxford, Oxford University Press, 2006.

${ }^{4}$ El título de la obra en la traducción de Diderot es Essai sur le Mérite et la Vertu, par Mylord $S^{* * *}$, y fue publicado en París, en 1745, con falso pie de imprenta (Amsterdam). El texto original de Shaftesbury fue editado, sin su consentimiento, por John Toland, en 1699. Luego, en 1711, formó parte del segundo de los tres tomos que reunían sus Characteristics of men, manners, opinions, times. Sobre la historia de esta obra, ver la Introducción en la edición David Walford, Oxford, Manchester University Press, 1977. 


\subsection{Escepticismo: el primer paso hacia la verdad.}

En un estudio sobre las primeras obras de Diderot, Jacques Chouillet localiza cuatro pasajes en la traducción del ensayo de Shaftesbury, publicada en 1745, en los que nuestro autor hace referencia al escepticismo. ${ }^{5}$ Sin embargo, Chouillet no repara en que dos de esos pasajes (AT: I, 23; I, 119) ${ }^{6}$ poco sirven para obtener información sobre el juicio de Diderot, puesto que son traducciones literales del término utilizado en la obra del filósofo inglés

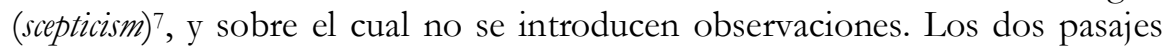
restantes (AT: I, 14; I, 119, nota 1), en cambio, sí pueden arrojar cierta luz sobre el asunto.

El primero de ellos es interesante porque Diderot traduce libremente ${ }^{8}$ un párrafo en el que no aparece explícitamente mencionado el escepticismo. En el fragmento en cuestión, Shaftesbury debate con aquellos que oponen el teísmo al cristianismo, y señala: "como si nuestra religión fuera una especie de culto mágico [Magik - culte magique], que no dependiera de la creencia en un único Ser superior; o como si la firme y racional creencia en un tal Ser, sobre fundamentos filosóficos, fuera una limitación para creer algo más". A continuación, advertirá acerca de las consecuencias de tal posición: "Excellent presumption, for those who naturally incline to the disbelief of revelation, or who through vanity affect a freedom of this kind?" La traducción libre de Diderot dice: "Certes ce serait donner beau jeu à ceux qui, soit par scepticism, soit par vanité, ne sont déjà que trop enclins a rejeter tout revelation". Como puede notarse, Diderot decide traducir por escepticismo lo que en el texto de Shaftesbury es una inclinación natural a la

5 Cfr. Chouillet, J., "Le personnage du sceptique dans les premières oeuvres de Diderot (1745-1747)", en Dix-Huitième Siècle, 1, pp. 195-212.

${ }^{6}$ Citamos la obra de Diderot en la edición de Assézat-Tourneux (AT), seguida del $n^{\circ}$ de volumen y el $\mathrm{n}^{\mathrm{o}}$ de página.

7 Shaftesbury, A. A. C. Earl of (1711), Characteristics of men, manners, opinions, times, Vol. II, “An Inquiry Concerning Virtue and Merit”, (ed. de 1790), Basil, p. 142.

8 En su Discurso Preliminar a la traducción de la obra, Diderot advierte claramente sobre "la manera en que he tratado a M... S... Lo he leído y releído: me he impregnado de su espíritu; y he cerrado su libro, por decirlo así, cuando tomé la pluma. Jamás se ha utilizado a otro con tanta libertad", p. 16. 
incredulidad. Lo importante de esta traducción es que Diderot no parece estar pensando en el escepticismo de sistema, como sí lo hará en el segundo pasaje, que veremos a continuación, sino más bien en una cuestión de temperamento. ${ }^{9}$

Hacia el final de su obra Shaftesbury hace una referencia a los límites del escepticismo ${ }^{10}$ y Diderot establece una pausa allí para introducir un largo comentario en nota al pie:

¿Con qué objeto prescribirme reglas de conducta, dirá tal vez un pirrónico, si yo no estoy seguro de la sucesión de mi existencia? ¿Se me puede demostrar alguna cosa para el futuro, sin suponer que yo continúe siendo yo? Pues, eso es lo que niego. Yo, que pienso en el presente ies el yo que pensaba hace cuatro días? El recuerdo es la única prueba que tengo de ello. Pero, cien veces creí recordar lo que jamás había pensado; tomé como hecho constatado aquello que había soñado. (...) Sin embargo se actúa como si nada fuera más verdadero: hasta el pirrónico deja estas sutilezas a la salida de la escuela y sigue el tren común.

En este caso, Diderot advierte que la práctica exagerada del escepticismo, que en el ejemplo citado se percibe en la insistencia del pirrónico por llevar las dudas hasta sus últimas consecuencias, únicamente puede conducir al absurdo. Éste es para Diderot el escepticismo de sistema, que sólo se entretiene llevando a cabo una batalla dialéctica sin obtener de ella fruto alguno. ${ }^{11} \mathrm{El}$ escéptico es inconsecuente porque, como vemos en la última parte de la cita, no puede dejar de vivir de acuerdo con la guía del

${ }^{9}$ En este mismo sentido, Diderot dirá en los Pensées (XXIII) que existe una inclinación temperamental.

10 "For let us carry scepticism ever so far; let us doubt, if we can, of every thing about us; we cannot doubt of what passes within ourselves". Op. cit., p. 142.

${ }^{11}$ En realidad, la versión caricaturesca del pirrónico que niega las cosas más evidentes para el sentido común, muy difundida desde que el escepticismo reaparece hacia finales del Renacimiento, impide a los detractores de esta corriente comprender el valor de la ataraxia y conlleva a la disolución -o, en todo caso, a la resignificación- de un vínculo que para los antiguos era esencial, el de la teoría y la praxis. 
sentido común, independientemente de lo que su incertidumbre teórica le indique. Casi un año más tarde, en la obra que sigue a esta traducción, Diderot retomará las críticas al escéptico, pero introduciendo nuevas distinciones y admitiendo que, en tanto se considere como una actitud crítica hacia las creencias y las verdades recibidas, el escepticismo es indispensable para la filosofía.

Los Pensamientos filosóficos comenzaron a circular clandestinamente en la primavera de 1746. La obra había sido publicada en forma anónima y con un falso pie de imprenta. La clandestinidad del escrito, como nos recuerda Roland Mortier, tenía como función ocultar y poner al resguardo de la censura a su autor, como así también a su verdadero editor, Durand. ${ }^{12}$ Para el 7 de julio de ese mismo año, el Parlamento de París condenaba el opúsculo por escandaloso y, simbólicamente, hacía quemar un ejemplar en público. Como era de esperar, eso no hizo más que avivar el interés del público lector, y una veintena de ediciones le sucedieron en el transcurso del siglo XVIII. Pero el éxito de los Pensamientos no estaba solamente ligado a la censura del Parlamento, había razones de orden estilístico que hacían que sus ideas puedan ser asimiladas y transmitidas fácilmente, como señalaba Turgot: “[L]a erudición aburre; la metafísica repele. Una buena palabra se retiene y pasa de boca en boca: su veneno, si me atrevo a decirlo, más volátil, se esparce por el aire y penetra por la sola respiración". ${ }^{13}$ Aunque Diderot no pretendía que sus ideas estuvieran al alcance de todos -el subtítulo da cuenta de ello: "Piscis hic non est omnium",$-{ }^{14}$ la fragmentación de sus pensamientos en 62 parágrafos y la corta extensión del conjunto hacían de la obra, a diferencia de otras más densas, como por ejemplo la Carta sobre los ciegos, un texto accesible incluso

12 Mortier, R. "Lectura de Roland Mortier", en Diderot, D., Pensées philosophiques, Collection Les philosophiques, Paris, Actes Sud- Lemeac, 1998, p. 63. En adelante utilizaremos esta edición. Las traducciones son nuestras, a menos que se indique lo contrario.

13 El pasaje está tomado de la reseña que Turgot había escrito poco después de la aparición de la obra. Citado en Morin, R., Les Pensées philosophiques de Diderot devant leurs principaux contradicteurs au XVIII siècle, Paris, Belle Lettres, 1975, p. 9.

14 "Este pescado no está destinado a todos". 
para los detractores menos lúcidos. ${ }^{15}$ En efecto, según el estudio de Morin, de entre las obras de Diderot, sólo l'Encyclopédie recibió una cantidad mayor de críticas violentas, y eso sin contar, por supuesto, que no todas las de esta última iban dirigidas hacia él, puesto que muchos de los artículos censurados provenían de otras plumas.

Los censores del Parlamento tenían buenos motivos para condenar los Pensamientos, pues se podía encontrar en ellos un arsenal de ideas que atacaban sin reparos a la religión positiva, adoptando un dé́smo que se presentaba como única opción para enfrentarse al ateísmo. No había en estas ideas novedad alguna; la numerosa literatura clandestina de principios de siglo y el deísmo ya ampliamente teorizado entre los británicos y que había sido importado a Francia especialmente por Voltaire, proveían un sinnúmero de ejemplos para los argumentos que utiliza Diderot. La novedad radicaba en el modo en que se los presentaba y, como vimos, en el estilo de escritura fragmentada.

Lo que nos interesa aquí es mostrar cuáles eran los motivos de la adhesión de Diderot al deísmo y por qué, de acuerdo con su opinión, la metafísica ya no estaba en condiciones de enfrentar al ateo. En primer lugar, digamos que no está del todo decidido si el deísmo de Diderot era sincero o si ocultaba una simpatía, pero no más que eso, hacia el ateísmo. ${ }^{16}$ Desde nuestro punto de vista, todo parece indicar que el director de la Encyclopédie creía que el deísmo era preferible a cualquier otro intento de fundamentar la religión, pues las sutilezas de las escuelas resultaban inútiles para convencer al escéptico (XVI); "Un Cudworth, un Shaftesbury, habrían resultado mil veces más embarazosos para un Vanini que todos los Nicole y los Pascal del mundo" (XIII). Sin embargo, los argumentos de los ateos pueden poner en aprietos al deísta cuando entra en consideración, en el argumento del diseño,

${ }^{15}$ Cfr. Morin, R., Op. cit., Cap. 1: “L'accueil des "Pensées philosophiques”, pp. 9-19.

16 René Etiemble, más contundentemente, sostuvo que Diderot era ateo desde sus inicios y que el deísmo presentado en los Pensées fue una máscara para ocultar aquélla posición. Ver.: Etiemble, R., "Structure et sens des Pensées philosophiques", Romanische Forschungen, $74: 1 / 2$, pp. 1-10. 
el cálculo de probabilidades (XXI). Más allá de estas vacilaciones, lo que parece más seguro es que Diderot estaba convencido de que lo que hasta el momento pretendía decidirse en el campo de las especulaciones ontológicas y metafísicas sólo podía ser resuelto apelando a la experiencia. Y esta experiencia es la de la ciencia; más precisamente, la de la física experimental:

Los grandes golpes que ha recibido el ateísmo no proceden de la mano de un metafísico. Las meditaciones sublimes de Malebranches y de Descartes eran menos adecuadas para conmover el materialismo que una observación de Malpighi. ${ }^{17}$ Si esta peligrosa hipótesis se tambalea en la actualidad, hay que atribuirle el honor a la física experimental. No es sino en las obras de Newton, Musschenbroek, Hartsoeken y Nieuwentyt ${ }^{18}$ donde se han encontrado las pruebas satisfactorias de la existencia de un ser soberanamente inteligente (XVIII).

Esa "hipótesis peligrosa" que representa el materialismo se tambaleaba, según Diderot, porque no podía explicar el mundo con independencia de un creador. La experiencia científica muestra que la complejidad del universo, las leyes que lo gobiernan y los seres que lo habitan, sólo pueden ser explicarse a partir de un "ser soberanamente inteligente". Pero más importante para Diderot era el hecho de que la experimentación sobre la generación de organismos vivos cerraba las puertas a la tesis materialista que postulaba la autosuficiencia de la materia y prescindía así de un agente que interviniera desde el exterior:

17 Médico y biólogo. Sus descubrimientos y estudios sobre la circulación de la sangre confirmaron las teorías de William Harvey; la experimentación con larvas y gusanos le valió el nombre de inventor de la anatomía microscópica.

18 Su obra más conocida tuvo seis ediciones y fue traducida al inglés y al francés: De l'existence de Dieu démontrée par les merveilles de la nature, ou traité téléologique dirigé contre la doctrine de Spinoza par un médecin hollandais, en 1718, tres años después de su publicación original. 
Las sutilezas de la ontología han producido, a lo sumo, escépticos; al conocimiento de la naturaleza es al que le estaba reservado hacer grandes deístas. El solo descubrimiento de los gérmenes ha disipado una de las más poderosas objeciones del ateísmo. Actualmente estoy convencido de que, sea el movimiento esencial o accidental a la materia, sus efectos acaban con sus desarrollos: todas las observaciones coinciden en demostrar que la putrefacción, por sí sola, no produce nada organizado (XIX).

Aun admitiendo que el movimiento sea esencial a la materia, hipótesis que seguía siendo discutida por entonces, la generación de la vida no podía pensarse como espontánea. Hacía falta algo más que la materia, su movimiento y las leyes de la mecánica para explicar la aparición de los seres organizados. En cualquier caso, la experiencia científica se convierte para Diderot en juez último de las discusiones metafísicas. Las especulaciones pueden, sin contradicción, proyectarse sobre la naturaleza, pero allí donde tropiecen con hechos contrarios, demostrados por la ciencia, serán consideradas como falsas. Precisamente por este motivo el parágrafo se cierra con una referencia a la modificación que supuso en el debate el descubrimiento de los gérmenes: "Si un ateo hubiera propuesto, hace doscientos años, que quizá un día se viera salir a los hombres completamente formados desde las entrañas de la tierra, como se ve nacer un enjambre de insectos de un trozo de carne podrida, me gustaría saber lo que podría haberle contestado un metafísico" (XX).

Éste es el pasaje que mejor representa el potencial de la ciencia. Antes de realizarse experiencias sobre la generación de los organismos vivos y demostrar que "la putrefacción, por sí sola, no produce nada organizado", la metafísica carecía de argumentos y hubiera sido impotente para contrarrestar las tesis de los materialistas. Si en el terreno de las creencias religiosas "las sutilezas de la ontología han producido, a lo sumo, escépticos", entonces, deberá ser tarea de la ciencia revertir la situación. Unos parágrafos antes, Diderot había sostenido que "todas las frivolidades de la metafísica no valen lo que un argumento ad hominem", que no sirven para convencer y que, a veces, es necesario "despertar el sentimiento físico o moral". Y relataba allí mismo, en tono de burla, que "fue con un bastón como se probó al pirrónico que estaba equivocado al negar su existencia" (XVII). En cuanto a la existencia de Dios, el escéptico debe ser combatido con tanta evidencia como 
sea posible y esa es, creemos, la función que cumple el deísmo en los Pensamientos.

Sin embargo, Diderot está enfrentándose a un escéptico indolente (XXVIII) que "duda porque no conoce las razones para creer" y que, por lo tanto, "no es sino un ignorante" (XXIV). A continuación, en cambio, aparecerá la concepción del escepticismo como actitud crítica, como posición frente a las creencias y verdades establecidas. Quien practica este tipo de escepticismo "ha contado y sopesado las razones" (XXIV) y está, por lo tanto, dispuesto a discutir racionalmente sus propias creencias. Es un escepticismo que no conviene a todo el mundo, pues algunos "prefieren aventurar una elección a no hacer ninguna" y "se aseguran de todo, aunque no hayan examinado nada cuidadosamente: no dudan de nada, porque no poseen ni la paciencia ni el valor necesarios" (XXVIII). Diderot definirá al nuevo escéptico en pocas líneas:

¿Qué es un escéptico? Es un filósofo que ha dudado de todo lo que cree, y que cree lo que un uso legítimo de su razón y de sus sentidos le ha mostrado como verdadero. ¿Queréis algo más preciso? Haced sincero al pirrónico y tendréis al escéptico $(\mathrm{XXX})$. Lo que nunca ha sido puesto en duda no puede ser de ninguna manera demostrado. Lo que no ha sido examinado sin prevención no ha sido jamás bien examinado. El escepticismo es, por lo tanto, el primer paso hacia la verdad (XXXI).

Como vemos, el escéptico es ahora el representante de la actitud que debe tener el filósofo ideal, y Diderot se reconoce escéptico cuando declara que "se me debe exigir que busque la verdad, pero no que la encuentre" (XXIX). Allí donde la balanza no se incline hacia uno de los lados y la razón no se vea arrastrada a tomar una posición por la fuerza de un argumento o de una evidencia, el juicio del filósofo permanecerá en suspenso, aunque siempre dispuesto a continuar en el examen de la materia que trata, pues, ante todo, está comprometido con la búsqueda de la verdad.

Decíamos que el escepticismo, en cuanto actitud crítica hacia las creencias, representa el ideal de filósofo, pero no es que Diderot estuviera forjando un nuevo ideal; para él, la figura del escéptico ya había sido encarnada a la perfección por uno de los héroes del pensamiento ilustrado, 
Pierre Bayle. El artículo "PYRRHONIENNE ou SCEPTIQUE Philosophie", redactado por Diderot para la Encyclopédie, contiene pasajes en los que no se ocultaba su admiración por el autor del Dictionnaire historique et critique:

Pero el Escepticismo no tuvo ni entre los antiguos, ni entre los modernos ningún atleta más temible que Bayle. [...] La naturaleza le dio la imaginación, la fuerza, la sutileza, la memoria, y la educación, todo lo que puede contribuir a despertar las cualidades naturales. [...] Bayle tuvo pocos iguales en el arte de razonar, quizá ninguno superior. Nadie supo captar más sutilmente la debilidad de un sistema, nadie supo hacer valer con mayor fuerza sus ventajas; temible cuando demuestra, más temible aún cuando objeta. ${ }^{19}$

La valoración del escepticismo en los Pensamientos filosóficos es, como vimos, ambigua. Sin embargo, Diderot distingue claramente entre el semiescepticismo (XXXIV) y la actitud escéptica. Las corrientes de la filosofía ilustrada de principios del siglo XVIII hicieron de esta actitud la piedra de toque de su filosofía y Diderot dará en varias ocasiones muestra de aprecio a quienes la sostienen. Como veremos más adelante, será justamente esta actitud la que permita que en el camino de los castaños, uno de los caminos por los que deambulan los personajes de El paseo del escéptico, se reúnan los partidarios de las distintas sectas filosóficas en la más apacible convivencia y tolerancia mutua.

\section{$1.3 \mathrm{El}$ paseo del escéptico}

19 Diderot, D. et d'Alembert, J. (eds.) (1751-1767), Encyclopédie ou Dictionnaire raisonné des sciences, des arts et des métiers, par une Société de Gens de Lettres, Paris, chez Briasson, David, Le Breton, Durand, Vol. XIII, pp. 612-13. 
La promenade du sceptique ${ }^{20}$ es la segunda obra original de Diderot y fue escrita a comienzos de 1747. Había tomado la prudente decisión de no darla a conocer en esos años, por lo que guardó el manuscrito con la intención de publicarla en un momento más oportuno. Y es que, por entonces, el filósofo ya figuraba entre los autores peligrosos. En una carta del cura de SaintMédard, Pierre Hardy de Levaré, en la que presenta sus quejas ante Berryer, teniente general de la policía, se encontraban los motivos por los cuales era visto como un personaje indigno de confianza:

Monsieur Diderot es un hombre que llevó una vida licenciosa durante su juventud. [...] Los comentarios que suele hacer Diderot en su casa demuestran con claridad que es deísta, si no algo peor. Blasfema contra Jesucristo y la Santa Virgen de un modo que yo no osaría poner por escrito. Es cierto que nunca he hablado con este hombre y que no lo conozco personalmente, pero me han dicho que es muy ingenioso y que su conversación es amena. En una charla reconoció que había sido el autor de una obra condenada por el Parlamento y quemada hace dos años [Pensées philosophiques]. Me han informado de que hace más de un año que está escribiendo otra obra todavía más peligrosa para la religión. ${ }^{21}$

La obra que tanto alarmaba al cura de Saint-Médard era precisamente La promenade du sceptique. Un oficial de la policía, que ya había sido puesto al tanto del asunto,22 aprovechó mientras Diderot cumplía su condena en la prisión de Vincennes, en 1749, para interrogarlo por el original. Diderot le juró que lo había quemado, pero en realidad, según sabemos por una carta de

20 Utilizaremos aquí la edición de Assézat et Tourneaux, Op. cit., I: 177-251. Indicaremos entre paréntesis la página de referencia luego de cada cita. La traducción és Gitedtuapor Furkbank, P., Diderot. Biografía Crítica, Barcelona, Emecé, 1992, p. 67.

22 Darnton muestra que la práctica de los informantes, como el que tenía el cura para espiar a Diderot, era muy habitual en la época. La policía tenía varios de ellos a sueldo, cuya tarea era seguir y espiar a los espíritus sospechosos y elaborar fichas sobre sus actividades. Cfr. Darnton, R., Op. cit., Cap. IV. "Un inspector de policía organiza su archivo: la anatomía de la república de las letras”, pp. 148-86. 
su hija, Angélique Vandeul, a Meister, ese original había sido confiado al cuidado del mismísimo Berryer. ${ }^{23}$ Posteriormente, el manuscrito pasó por varias bibliotecas privadas y, a pesar de los intentos que hizo Diderot por recuperarlo, permaneció entre archivos por mucho tiempo, hasta que, finalmente, fue editado por Paulin en 1830.

Diderot sugirió, en el Discurso preliminar de la obra (p. 180), un título alternativo, más descriptivo y adecuado que el original: Diálogo sobre la Religión, la Filosofía y el Mundo. Ariste, el narrador en la ficción, es un joven que se destacó en la carrera militar, aunque siempre tuvo un "gusto natural por el estudio de la filosofía y de las bellas letras" (p. 177). Recuerda en el Discurso su visita a Cléobule, un filósofo que se había retirado a vivir en una sencilla residencia de campo y cuyos discursos lo maravillaron tanto que, de regreso a su casa, se dedicó con urgencia a escribirlos (p. 180). En la campiña donde vivía Cléobule había un parterre, menos extenso que irregular, donde concurrían tres caminos -el camino de las espinas (l'allée des épines), el de los castaños (l'allée des marronniers) y el de las flores (l'allée des fleurs)- dispuestos de tal manera que formaban, junto al parterre, una especie de estrella (p. 178). El lugar inspiró a Cléobule para relatar una historia didáctica a Ariste: cada uno de esos caminos iba a ser transitado por grupos de personas que representaban un modo de vida diferente: la vida religiosa, la vida filosófica y la vida mundana, respectivamente.

Dos cuestiones nos interesan tratar en esta obra. La primera de ellas es la descripción de los paseantes del camino de los castaños, que nos brindará la oportunidad de volver al tema del escepticismo como espíritu crítico, como así también nos permitirá tomar nota de cómo veía Diderot el mundo de las sectas filosóficas de su tiempo. La segunda cuestión se relaciona con el giro ilustrado respecto de la función social del filósofo y será trabajada a partir del análisis del diálogo que Ariste recuerda haber mantenido con Cléobule, reproducido en el Discurso preliminar. Pero antes de comenzar con estos temas, presentaremos la estructura de la obra y mostraremos brevemente algunas características del camino de las espinas.

${ }^{23}$ Cfr. Cain, J. (ed), Diderot, Paris, Bibliothèque Nationale, 1963, p. 13. 
La promenade se divide en dos grandes partes: la primera es el Discurso preliminar, en el que Ariste cuenta el origen del texto que está por presentar y recuerda una discusión que tuvo con Cléobule acerca de su publicación; la segunda parte es el paseo que Cléobule relata a Ariste y que éste escribe con el fin de darlo a conocer. Esta última parte se subdivide en tres capítulos, en cada uno de ellos se describe, a través de los diálogos de los protagonistas, las características principales de los caminos y de los estilos de vidas que representan. Sin embargo, esta descripción no es directa, sino por medio de un lenguaje alegórico que Cléobule se ingenió para poner sus ideas al alcance de Ariste. En efecto, aquél había estimado que utilizando términos y comparaciones propias del arte militar, las sutilezas de su discurso se volverían más comprensibles para su amigo.

Luego de advertirle de que no va a discurrir sobre el provecho que, dentro de dos o tres mil años, obtendrán las ciencias de sus descubrimientos, Cléobule le adelanta a Ariste el objeto de su narración: "me propongo un fin más noble, una utilidad menos lejana. La de ilustrar, de perfeccionar la razón humana mediante el simple relato de un paseo" (p. 189). Así comienza:

El imperio del que te hablo [este mundo] está gobernado por un soberano sobre cuyo nombre sus súbditos están más o menos de acuerdo, pero no lo están de igual modo acerca de su existencia. Nadie lo vio, y, entre sus favoritos, aquéllos que pretenden haber tenido conversaciones con él, hablaron de una manera tan oscura, le atribuyeron contrariedades tan extrañas, que mientras que una parte de la nación se esforzaba en formar sistemas para explicar el enigma, o en destrozarse entre ellos para hacer prevalecer su opinión, la otra tomaba el partido de dudar de todo lo que allí se decía, y algunos el de no creer en nada (p. 190).

Cléobule presenta la escena del relato. La división hecha aquí entre las distintas partes de la nación parece no hacer referencia a quienes siguen el sendero de las flores. El contraste entre los habitantes del imperio se reduce más bien al de los religiosos y los filósofos. En efecto, el camino de las flores tiene un interés filosófico secundario y Diderot lo utiliza para mostrar la superioridad que la vida del filósofo tiene en relación con la vida mundana, caracterizada, básicamente, por el cinismo. 
El relato continúa reforzando la analogía militar. Después de considerar cómo fuimos reclutados para el ejército sin nuestro consentimiento (el bautismo) (p. 192), Cléobule describe la morada del rey y la misión de los soldados:

Él habita, se dice, en una estancia luminosa, magnífica y afortunada de la cual tenemos descripciones tan diferentes entre sí como las imaginaciones de aquellos que la concibieron. Allí vamos todos. La corte del príncipe es un punto de encuentro general hacia donde marchamos continuamente, y se dice que seremos recompensados o castigados según la buena o mala conducta que hayamos tenido durante el trayecto (p.192).

Es inevitable llegar a ese punto de encuentro, lo que no está determinado es por cuál de los tres caminos se transitará. El de las espinas, es un camino "que pasa por el más seguro y que no es en verdad sino el más penoso. Es un pequeño sendero largo, recto, escarpado, repleto de piedras y de espinas". El camino de las flores, en cambio, es "espacioso, agradable, todo cubierto de flores, y su pendiente parece suave". Sin embargo, si el caminante presta atención notará que es "desigual, tortuoso y poco seguro". El tercer camino, el de los castaños, es "sombreado, rodeado de castaños, arenoso, más cómodo que el sendero de las espinas, menos agradable que el camino de las flores, más seguro que uno y otro, pero difícil de seguirlo hasta la meta, puesto que su arena se vuelve movediza al final" (p. 193).

Como en todo gobierno militar, se instituyeron signos que permitían reconocer a quienes abrazaban la profesión de las armas y se establecieron castigos para quienes desertaran sin orden o sin necesidad (p. 192). Las marcas distintivas de este ejército fueron una túnica o casaca blanca y una venda sobre los ojos. Permitir que la túnica se manche (el pecado) o deshacerse de la venda (apartarse de la fe) eran los indicios más claros por los cuales se reconocía a los desertores. Al nacer, todos se encuentran en el camino de las espinas, aunque no todos permanecen en él.

\subsubsection{El camino de las espinas}


En este camino Diderot continúa la crítica a la religión positiva que había emprendido en los Pensamientos filosóficos, aunque el tono es notablemente más sarcástico. Los personajes que deambulan por allí pertenecen, en general, a "la raza más malvada que conozco", sostiene Cléobule. Son "orgullosos, avaros, hipócritas, deshonestos, vindicativos, pero sobre todo pendencieros" (p. 195). La exposición de la estructura jerárquica de la comarca, con su príncipe (Dios o Jesús, según el contexto), su virrey (el papa) y el cuerpo numeroso de guías y oficiales, cuyos rangos varían al infinito (los ministros de las órdenes) (p. 195-8), ponen en evidencia que la Iglesia romana es el blanco preferido de Diderot. Aunque el virrey diga ser el más humilde servidor de todos, admite de buena gana que sus satélites sostengan que todos son sus esclavos y, a fuerza de repetirlo, han convencido de ello a los idiotas, que representan el grueso de la comarca (p. 196). Sin embargo, Cléobule se remonta en el tiempo para narrar el surgimiento del ejército y, de ese modo, la crítica se extiende a toda religión revelada.

Luego de pasar revista por las diferentes rupturas y divisiones que sufrió la comarca, Cléobule se detendrá en la exposición del código militar, que "es una especie de pastiche, ejecutado por un centenar de obreros diferentes que han añadido pieza por pieza trozos de su gusto" (p. 200). El código se expresa en dos libros (Antiguo y Nuevo Testamento), a veces contradictorios y cuyas procedencias no se pueden comprobar. Unas líneas más arriba, Cléobule ironizaba acerca de estos dos libros:

Estos libros están escritos de una manera tan desigual, que parecería que [el rey] no fue muy cuidadoso en la elección de sus secretarios, o que a menudo se abusó de su confianza. El primero contiene reglamentos singulares, con una larga serie de prodigios obrados para su confirmación; y el segundo revoca estos primeros privilegios, estableciendo unos nuevos que están igualmente apoyados sobre maravillas: de ahí los litigios entre los privilegiados (p. 191).

Luego de relatar las aventuras del viejo pastor (Moisés), y sin abandonar el tono de burla, Cléobule dice que éste se dispuso a escribir una historia para su nación: es la primera parte del código (p. 201). El soberano hizo el primer soldado y "como la mujer que le concedió hizo una mala 
comida e imprimió a sus hijos y a todos sus descendientes una mancha negra que los volvía odiosos al príncipe", éste "hizo inundar todo", con la excepción de un cuartel militar cuyo jefe era un buen hombre (Abraham) (p. 201).

Cuando apareció el hijo del rey (Jesús), sus compatriotas lo vieron, durante mucho tiempo, como a cualquier otro hombre. "Pero un buen día se sorprendieron al escucharlo arengar, y arrogarse el título de hijo del soberano y el poder de abolir el antiguo código, a excepción de diez líneas contenidas allí, y substituirlo por otro" (p. 203). "Pretendía, por ejemplo, que cuando se tuvieran los ojos bien cubiertos por la venda, se vería, claro como el día, que su padre, él y un tercer personaje que era al mismo tiempo su hermano y su hijo, estaban tan perfectamente confundidos que no hacían más que un solo y mismo todo" (p. 204). Los primeros seguidores que fueron invitados a su mesa comieron abundantes manjares, y bebieron generosamente a su salud. Pero sus sucesores economizaron, pues

descubrieron, no sé cómo, que su maestro poseía el secreto de envolverse en una miga de pan, y de hacerse tragar entero, en un mismo instante, por un millón de amigos suyos, sin causar a ninguno de ellos la menor indigestión, por más que tuviera en realidad cinco pies con seis pulgadas de altura, y ordenaron que la cena fuera convertida en un almuerzo que se haría en seco. Algunos soldados alterados murmuraron. Se pasó a las injurias, luego a los golpes. Hubo mucha sangre derramada; y por esta división, que arrastró a otras dos, el camino de las espinas se vio reducido a la mitad de sus habitantes, y estuvo a punto de perderlos todos (p. 204).

Diderot continuará, por medio de Cléobule, atacando las creencias religiosas que mantienen a los temerosos habitantes del camino de las espinas con la venda sobre sus ojos. Veamos antes de pasar al camino de los castaños, un extracto de la conversación que sostuvieron Marc y Ménippe. Éste es un visitante en el camino de las espinas que proviene de los castaños y se muestra interesado en conocer más sobre la historia del hijo del rey. Marc, suponiendo que puede llegar a reclutar un soldado para su ejército, le cuenta entusiasmado todos los prodigios que su príncipe realizó y las máximas que predicaba. Cuando Ménippe retoma la palabra, dice: "Las máximas de vuestro 
jefe me gustan. Las encuentro conformes a las que enseñaron todos los hombres sensatos que han aparecido sobre la tierra más de cuatrocientos años antes que él. Las relatáis como nuevas, y lo son tal vez para un pueblo imbécil y grosero, pero son viejas para el resto de los hombres" (p. 209).

Diderot comienza de este modo con un arsenal de argumentos muy conocido por los filósofos de los castaños, argumentos que eran herencia de las obras del libertinismo erudito y que luego fueron retomados en los textos de los clandestinos que circulaban desde comienzos del siglo XVIII. ${ }^{24}$

La moral que predica el vocero de la religión revelada no tiene nada de nuevo, es tan vieja como la humanidad, es natural. Ahora bien, Ménippe admite que los prodigios sí representan una novedad, pero no ve cómo sólo un pequeño grupo de hombres haya sido testigo de ellos y los haya avalado: “¿Concebís de buena fe que, en un provincia del Imperio tan frecuentada como Judea, hayan sucedido cosas tan extraordinarias, y durante tres o cuatro años, sin que nadie haya oído nada acerca de ellas?” (p. 209). Para finalizar, veamos una cita que se cierra con una referencia explícita a uno de los clandestinos más leídos del siglo XVIII, el Tratado de los tres impostores25:

Considera que si vuestro jefe hubiera llevado a cabo la mínima parte de las cosas que le atribuís, el emperador, Roma, el Senado, toda la tierra se habría enterado. Este hombre divino se habría convertido en tema de nuestras conversaciones y objeto de nuestra admiración general. Sin embargo, todavía se lo desconoce. Esta provincia entera, a excepción de un pequeño número de habitantes, lo ve como un impostor (p. 210).

${ }^{24}$ Como nos recuerda Sébastien Charles, esta literatura compartía no sólo estrategias de difusión sino que también en ella se agrupaban los temas esenciales que se repetían casi sin excepción: discusión de la existencia de un Dios remunerador y vengativo; crítica del dogma de la inmortalidad del alma, rechazo de todo finalismo obrante en la naturaleza, etc. Cfr. Charles, S., «Liminaire », en Tangence, 81, 2006, pp. 5-13.

${ }^{25} \mathrm{La}$ fecha de redacción del manuscrito continúa siendo materia de discusión, aunque se supone que podría datarse alrededor de 1705. La obra ha sido editada en español por El cuenco del Plata, con traducción y prólogo a cargo de Diego Tatián, 2007. 


\subsubsection{El camino del castaños}

Comencemos con una observación sobre el modo en que Diderot pone en escena a los habitantes de esta comarca: la descripción que hace Cléobule de los transeúntes de este camino coincide, a grandes rasgos, con la que Ariste había hecho en el Discurso preliminar acerca de la residencia de Cléobule y la convivencia con sus amigos:

Es allí [en el retiro de Cléobule] donde disfruté cien veces de la deliciosa conversación de Cléobule y del pequeño número de amigos que allí se reúnen. (...) Es allí donde vi al pirrónico abrazar al escéptico, al escéptico alegrarse por el éxito del ateo, al ateo abrir su bolsa al deísta, al deísta ofrecer sus servicios al espinosista; en una palabra, todas las sectas de filósofos congregadas y unidas por los lazos de la amistad. Allí reside la concordia, el amor a la verdad, la verdad, la franqueza y la paz; es allí donde el escrupuloso, el supersticioso, el devoto, el doctor, el cura y la monja jamás han puesto un pie (p. 179)

allí

Por su parte, Cléobule, al presentar el camino de los castaños decía que

se forma una estancia tranquila, y se parece bastante a la antigua Academia. (...) [Su pueblo es] razonador de profesión, le gusta conversar e incluso discutir, pero sin esa acidez y esa obstinación con la que se vociferan fantasías en los alrededores. La diversidad de las opiniones no altera en nada aquí el comercio de la amistad, y no aminora el ejercicio de las virtudes. Se ataca a sus adversarios sin odio, y aunque se los instiga sin miramientos, se triunfa sin vanidad (p. 215). Los soldados que toman esta ruta (...) la siguen en secreto y harían su viaje muy pacíficamente, si no fueran asediados y molestados de vez en cuando por los guías del camino de las espinas, que los ven como sus enemigos más peligrosos (p. 216).

El lugar que describen tanto Ariste como Cléobule no existe realmente, por supuesto. Forma parte del escenario que presenta la ficción y cumple su función dentro del escrito. Sin embargo, creemos, es posible que Diderot 
haya intentado recrear mediante su relato el ambiente filosófico de la Ilustración, tal como él lo veía. Dicho de otro modo, con La promenade du sceptique, Diderot habría otorgado existencia física a un espacio que carecía de ella y que se concebía como una república invisible. Nos referimos, claro está, a la République des Lettres, cuyos orígenes pueden remontarse hasta mediados del siglo XVI. ${ }^{26}$ Es difícil no ver en estas descripciones de Diderot un eco lejano de las palabras con las que Bayle se refería a ese espacio ideal: "esta república es un estado extremadamente libre. No se reconoce allí más que el imperio de la razón y de la verdad, y bajo sus auspicios, se hace la guerra inocentemente a quien sea"27.

Además de la representación física de la República y de la caracterización de sus habitantes, están los temas que se trataban. Ariste recuerda en el Discurso que...

[Cléobule] nunca dejaba de conversar conmigo de los errores del espíritu humano, de la incertidumbre de nuestros conocimientos, de la frivolidad de los sistemas de la física y de la vanidad de las especulaciones sublimes de la metafísica. (...) Me hablaba de la inconsistencia de nuestras afecciones, de la fragilidad de nuestras virtudes, de la fuerza de las pasiones, de las agitaciones de nuestra alma, de la importancia y de la dificultad de considerarse sin prejuicios y conocerse bien (p. 179).

${ }^{27}$ Fernando Bahr ha mostrado las mutaciones que esta República fue sufriendo desde su origen hasta la Revolución francesa, mutaciones que afectaban algunas de sus características, e incluso al modo en que se la representaban sus habitantes, aunque nunca lo suficiente como para impedir que se perciba su continuidad substancial en el tiempo. Cfr.: "El poder intelectual en la Europa moderna. Esbozo de una historia de la República de las letras", en J. De Zan y F. Bahr (Eds.) (2008), Los sujetos de lo politico en la filosofia moderna y contemporánea, Buenos Aires, UNSAM EDITA, Jorge Baudino Ediciones, pp. 57-79.

${ }_{27}$ P. Bayle, "Catius", D, Dictionnaire historique et critique, citado en: Bahr, idem., p. 66. 
Lo curioso de esta cita es que Ariste menciona una serie de temas que son propios del escepticismo, ${ }^{28}$ mientras que Cléobule, como se descubrirá unas páginas más adelante, es un deísta. Ésto, como sugerimos más arriba, nos hace pensar que lo que reúne a las sectas en el camino de los castaños no es otra cosa que el espíritu crítico del escepticismo tal como lo vimos cuando analizábamos los Pensamientos filosóficos. En La promenade, esta actitud escéptica distingue a los caminantes de los castaños de los de las espinas, y se simboliza en la falta de venda sobre los ojos. En los Pensamientos veíamos que Diderot diferenciaba al "semiescéptico" del escéptico verdadero. Lo hará del mismo modo en este texto, puesto que los escépticos son una secta más, entre otras que comparten el espíritu crítico. Veamos cómo presenta Cléobule la secta de los pirrónicos, o, digamos, "escépticos profesionales":

Está compuesta por gente que te dicen abiertamente que no hay ni camino, ni árboles, ni transeúntes; que todo lo que se ve bien podría ser cualquier cosa, y que también podría no ser nada. Tienen, se dice, una maravillosa ventaja para el combate, pues se libraron de la tarea de protegerse; no se ocupan sino de golpear. No tienen ni casco, ni escudo, ni coraza, sino sólo una espada corta de doble filo, que manejan con extrema destreza. Atacan a todo el mundo, incluso hasta sus propios camaradas, y cuando te han hecho largas y profundas heridas, o se han cubierto de heridas ellos mismos, sostienen con una prodigiosa sangre fría que todo eso no era más que un juego, que no tuvieron cuidado de lanzarte golpes, puesto que no tienen espada y que tu mismo no tienes cuerpo; que, después de todo, bien podrían equivocarse ( $\mathrm{p}$. 216).

Este escéptico se parece mucho a aquél que encontraba argumentos para poner en suspenso la continuidad de su yo, en la nota al pie de la obra de Shaftesbury que vimos en el apartado anterior. Pero aquí, a diferencia de lo

28 Todos estos temas se encuentran en los autores más representativos del escepticismo, como Montaigne, Charron, Bayle, pero también abundan en la literatura clandestina de principios del siglo XVIII. Pensamos, por ejemplo, en las Doutes des Pyrrhoniens, entre otros tantos. 
que sucedía en ese pasaje y en los Pensamientos, Diderot no ve a los escépticos como enemigos a combatir. Por el contrario, Cléobule recomienda a Ariste que no se ponga en guardia frente a ellos, que quizás las querellas que emprenden no son más que "una muestra de su amistad" (p. 216). El giro es notable y, de acuerdo con nuestra interpretación, la inclusión de la secta de los pirrónicos en el camino de los castaños es una clara señal del objetivo de la obra: que no debemos perder el tiempo en enfadarnos con los escépticos, puesto que nuestros enemigos están en el camino de las espinas. Por lo demás, siguiendo la costumbre de la época, los escépticos son caricaturizados y ridiculizados: "se cuenta que su primer capitán [Pirrón] chocaba bruscamente contra los paseantes y los árboles, que se caía en los pozos, se lesionaba y respondía a quienes se ofrecían a guiarlo que no se había movido de su lugar y que se encontraba muy bien" (p. 217). La presentación se cierra con un guiño: "estos soldados son buenos para las emboscadas y los estratagemas". Diderot conocía muy bien las ventajas del escepticismo para las disputas, las había aprendido de uno de los "campeones" de la secta, el mismo que imaginó un estandarte para sus camaradas: "una balanza bordada en oro, plata, lana y seda, con estas palabras como divisa: Que sais-je?” (p. 217).

Antes de finalizar este apartado, veremos qué otras sectas deambulan en el camino de los castaños para conocer cómo percibía Diderot lo que estaba pasando a su alrededor en cuanto a corrientes filosóficas se refiere.

La siguiente secta es menos numerosa que la de los escépticos y está conformada por soldados rebeldes que antes pertenecieron a aquélla. Estos guerreros reconocen "que existen, que hay camino y árboles, pero sostienen que las ideas de regimiento y fortaleza son ridículas, e incluso que el príncipe es una quimera", y sostienen "que la venda es la prenda de los idiotas y que el miedo al castigo actual es la única buena razón que se tiene para conservar su uniforme sin manchas" (p. 217). Cléobule se está refiriendo, claro está, a los ateos. Con relación a la última línea de la cita, que trata sobre las razones que conducen a los ateos a respetar las leyes de convivencia social, haremos la siguiente observación. Cléobule había advertido a Ariste que quedaba una cuestión cuya resolución dejaría en sus manos una vez que le hubiera trazado las características de todos los guerreros del camino de los castaños: "determinar si esta parte del ejército forma un cuerpo y si puede formar una sociedad". Y es que allí "no hay ni templos, ni altares, ni sacrificios, ni guías. 
No se sigue un estandarte común; no se conocen reglamentos generales" (p. 216). ¿Es posible que subsista una sociedad de ateos? ¿Cuál sería el lazo que mantendría cohesionados a sus ciudadanos? Este problema recorrerá gran parte de la obra de Diderot y en su Diálogo con la mariscala, de 1776, ofrecerá una respuesta positiva, fundamentada, por un lado, en el beneficio tanto privado como público que se sigue de actuar conforme a la virtud, y por otro, en el argumento que Cléobule atribuye a los ateos en la cita, es decir, el temor al castigo, al aparato regulador del Estado, la ley civil.

La siguiente secta es la de los deístas. Cléobule se enrolará en ella y, según parece, es la posición que asume Diderot, pues es la que defiende con mayores argumentos. Éstos

piensan todo de otro modo [que los anteriores]. Persuadidos de la existencia de la fortaleza, creen que la sabiduría infinita del príncipe no los ha dejado sin luces, que la razón es un presente que tienen de él y que es suficiente para reglar su marcha; que hay que respetar al soberano, y que se será bien o mal recibido según se haya servido bien o mal en el trayecto; que además su severidad no será excesiva, ni sus castigos ilimitados; y que una vez llegados al punto de encuentro no se saldrá más de allí. Se someten a las leyes de la sociedad, conocen y cultivan las virtudes, detestan el crimen, y consideran las pasiones bien administradas como necesarias para la felicidad. A pesar de la suavidad de su carácter, se los aborrece en el camino de las espinas. Y ¿por qué? preguntarás. Porque no llevan la venda; sostienen que dos buenos ojos alcanzan para conducirse bien, y porque piden ser convencidos por razones sólidas de que el código militar es verdaderamente la obra del príncipe, porque observan allí rasgos incompatibles con las ideas que tienen de su sabiduría y de su bondad (p. 218).

Deístas y ateos serán rivales en muchas de las discusiones que relatará Cléobule en este paseo. A ellos, se les sumará una secta que comenzaba a estar presente el pensamiento de Diderot: los espinosistas o materialistas. Sería exagerado sostener que éstos son presentados con simpatía por el narrador, pero los argumentos que defienden en las discusiones se parecen en mucho a los que, varios años más tarde, utilizará Diderot para crear el monstruo de El sueño de d'Alembert. 
Una cuarta banda te dirá que el paseo se realiza sobre las espaldas de nuestro monarca, imaginación más absurda que el Atlas de los poetas antiguos. Éste sostenía el cielo sobre sus hombros, y la ficción embelleció un error. Aquí se juega con la razón y con algunas expresiones equívocas para insinuar que el príncipe forma parte del mundo visible, que el universo y él no son más que uno, y que nosotros mismos formamos parte de su vasto cuerpo. El jefe de estos visionarios fue una especie de guerrillero que hizo frecuentes incursiones, y a menudo despierta la alarma en el camino de las espinas (p. 219).

La última de las sectas, si dejamos de lado la de los fanfarrones que sólo están de visita en este camino, es la de los egotistas. ${ }^{29}$ Estos soldados son muy singulares, pues

admiten la existencia de un solo ser, pero ese ser son ellos mismos: como todo lo que pasa en nosotros no es más que una impresión, niegan que exista otra cosa más que ellos y sus impresiones; así, son todos a la vez el amante y la amada, el padre y el hijo, el lecho de flores y quien lo camina (p. 220).

Estos personajes apoyan su disparatado sistema en una sola proposición: "sea que me eleve hasta los cielos, sea que descienda en los abismos, nunca salgo de mí mismo, y nunca es otra cosa que mi pensamiento lo que percibo". Cléobule está citando aquí a Condillac, cuya obra, el Ensayo sobre el origen de los conocimientos humanos, acababa de aparecer. Diderot conocía muy bien las ideas de Condillac -él mismo fue quien consiguió un editor para el Ensayo-, y comprendía el callejón sin salida al que conducían esas líneas. Lo que nosotros conocemos como el problema del solipsismo fue para Diderot una cuestión irresoluble. Este problema tiene, digamos, dos aristas: en cuanto problema práctico, para Diderot es un absurdo, un escepticismo burdo e impracticable en la vida real; sin embargo, desde un plano teórico este sistema es, "para vergüenza del espíritu humano y de la filosofía, el más difícil de 
combatir". ${ }^{30}$ Aunque en La promenade Diderot presenta el tema con algo de humor y no le atribuye mayor importancia a la secta, lo cierto es que representaba para él un serio problema: los egotistas son inmunes a una crítica racional, pues en ese campo tienen la batalla ganada; sólo se los puede combatir desde el sentido común, pero eso implica renunciar al entendimiento como juez de nuestra experiencia, un costo muy alto para las pretensiones del philosophe. El problema volverá a presentarse en otras oportunidades bajo el nombre de "el idealismo de Berkeley". Como ha señalado Miguel Benítez, el hecho de que Diderot haya retomado el tema en varios pasajes de su obra -Carta sobre los sordomudos; artículo "PYRRHONIENNE" de la Encyclopédie; Observaciones sobre Hemsterbuis; Ensayo sobre los reinados de Claudio y Nerón y dos cartas escritas en 1766- es un indicio del interés real que tuvo para él. ${ }^{31}$

Diderot ofrecerá una pintura más detallada de estas sectas y sus argumentos cuando las ponga en combate a través de las discusiones que se darán entre sus representantes y contra los religiosos. No creemos necesario ahondar en esas discusiones que, por lo demás, retoman los argumentos clásicos de la literatura clandestina que Diderot conocía a la perfección. Sólo nos resta un detalle, antes de salir del camino de los castaños, que consideramos importante para terminar de configurar el panorama filosófico del siglo XVIII. Se trata de un diálogo entre un religioso y un ateo en el que se debate sobre la existencia de Dios. Lo curioso aquí es el argumento que utiliza el religioso para convencer al ateo:

${ }^{30}$ Para un estudio sobre le surgimiento de los egotistas y de los debates que se dieron en torno a ellos, ver: Charles, S., "Skepticism and Solipsism in the EighteenthCentury: Revisiting the Egotist Question”, en Maia Neto, Paganini, Laursen (eds.) Skepticism in the Modern Age. Building on the Work of Richard Popkin, Leiden-Boston, Brill, 2009, pp. 325-43.

30 Diderot, D., Carta sobre los ciegos para uso de los que ven, trad. de J. Escobar, Valencia, Fundación Once y Pre-textos, 2002, p. 39.

31 Cfr.: Benítez, M., "La duda como método. Escepticismo y materialismo en la literatura clandestina del siglo XVIII en Francia", en El Basilisco, 15, 1983, pp. 44-61. 
-Convendrás conmigo en que debo al gran Espíritu la facultad de pensar, de razonar. Pienso, por lo tanto, existo. Yo no me he dado el ser. Me viene pues de otro, ése otro es el príncipe. -Se nota bien por ese rasgo, dijo riéndose el de los castaños [le marronnier], que tu padre te desheredó. Pero ¿qué uso haces de esa razón de la que tanto te jactas? Es entre tus manos un instrumento inútil (pp. 225-6).

Como vemos, Diderot pone en boca del religioso los argumentos cartesianos por excelencia: el cogito y la demostración teológica de la Tercera Meditación. Esto, creemos, vale como muestra de la pérdida de actualidad que la filosofía de Descartes tenía ya a principios de siglo. ${ }^{32}$ No sólo estos argumentos ya no le sirven a ninguna de las sectas de los castaños -pues los únicos que reconocen la existencia independiente de Dios, es decir los deístas, hacen uso del argumento del designio y no del cartesiano-, sino que, además, ahora son utilizados por sus enemigos. Así pues, no más Descartes; sólo resabios de su filosofía que los soldados de los castaños supieron utilizar para liberar sus propias batallas. Pirrónicos, ateos, deístas, materialistas e idealistas son los nuevos rostros visibles de la República invisible. Diderot los reúne en la residencia de Cléobule para hacerlos convivir y discutir pacíficamente, y nos ofrece con este relato la imagen de una época en la que la filosofía está en movimiento. El espíritu crítico es el único estandarte que reconocen los soldados de los castaños, un escepticismo sincerado, como señaló Diderot en los Pensamientos filosóficos.

\subsubsection{E1 giro ilustrado}

\footnotetext{
32 Sébastien Charles resume en pocas líneas el cambio que provocó el estudio del libertinismo filosófico en nuestra concepción de la filosofía moderna: "La investigación sobre el libertinismo filosófico y literario no ha dejado de ampliarse estos últimos años, obteniendo poco a poco sus cartas de nobleza y modificando la idea tradicional que se tenía de la edad clásica. Con el tiempo, una imagen nueva de esta época se impuso, en la que el cartesianismo no ocupa más el primer plano de un paisaje intelectual cuyos contornos, pero también l'avant-scène, han sido notablemente remodelados. Cfr.: Charles, S., Op. cit., 2006, p. 5.
} 
El Discurso preliminar de La promenade se inicia, como vimos, con un relato de Ariste en el que éste recuerda sus visitas a la estancia retirada de Cléobule. La última vez que fue a verlo, el filósofo le ofreció un discurso tan maravilloso que Ariste pensó que debía escribirlo para así poder publicarlo:

¡Cuántas verdades importantes y nuevas escuché! En menos de dos horas que nos llevó pasearnos desde el camino de las espinas al de los castaños, y desde el camino de los castaños a su parterre, expuso la extravagancia de las religiones, la incertidumbre de los sistemas de filosofía y la vanidad de los placeres del mundo. (...) De regreso a mi casa, no tuve nada más urgente que escribir su discurso. (...) Es este discurso que les entrego hoy bajo el título de El paseo del escéptico o de Diálogo sobre la Religión, la Filosofía y el Mundo (p.180).

La publicación del escrito se convertirá entonces en el asunto principal del Discurso. En este apartado, buscaremos mostrar, a partir del diálogo entre Ariste y Cléobule, cómo Diderot trata cuestiones capitales para comprender algunas de las transformaciones que se dieron en la Ilustración de mediados de siglo: la clandestinidad, la censura, la publicidad y el progreso. Ariste representa, en este sentido, al joven Diderot, promotor del cambio; Cléobule tiene rasgos que pueden emparentarlo con los esprits forts de la primera mitad del siglo XVII, pensamos en Charron o en La Mothe Le Vayer, aunque podemos decir simplemente que representa el conjunto de ideas que deben ser discutidas en función de la promoción del nuevo ideal de filósofo.

El primero de los asuntos que se trata es el de la necesidad de fijar el significado de un texto mediante la edición impresa. Precisamente, Ariste se asombra de las deformaciones que sufrieron los primeros ejemplares manuscritos que se habían puesto en circulación y decide, por eso mismo, ir a casa de Cléobule a solicitar su permiso para llevar el texto original a la imprenta:

Yo ya había impartido algunos ejemplares [de los manuscritos]; se multiplicaron, y vi la obra tan monstruosamente desfigurada en algunos, que temiendo que Cléobule, enterado de mi indiscreción, no me lo iba a agradecer, 
fui a prevenirlo, solicitar su perdón y obtener el permiso para publicar sus pensamientos (p. 181).

Diderot se enfrenta aquí con un problema real: la deformación de los manuscritos. María Susana Seguin ha mostrado, a través del estudio de un texto clandestino de la época y sus respectivas copias que:

El análisis de las diferentes copias de un mismo texto revela variantes significativas que no son solamente producto de los errores por parte de los copistas, sino de intervenciones de los lectores filósofos, dispuestos a reescribir los manuscritos que leen y que pueden, por eso mismo, cambiar de manera más o menos sensible la orientación filosófica del texto fuente, es decir, dar nacimiento a un nuevo tratado.

Diderot no exagera cuando denuncia las mutilaciones que sufrió el texto de Cléobule. Pero ¿por qué fijar el significado? La respuesta la encontramos en el modo en que Diderot pensaba su relación con la posteridad. En efecto, como puede verse en sus discusiones con Falconet, que conocemos a partir de la correspondencia entre ellos, Diderot entiende que la posteridad es un concepto que moviliza nuestra voluntad y nos compromete a hacer nuestro mejor esfuerzo. 33 "La posteridad es para el filósofo lo que el cielo es para el hombre de religión", había señalado Diderot. En el artículo "ENCYCLOPÉDIE", redactado por él para la Enciclopedia, se mostraba preocupado por la transmisión de los conocimientos a las futuras generaciones, y cuando hablaba de las ilusiones que se ponían en juego con la publicación de la obra colectiva, advertía: "Pero el conocimiento de la lengua es el fundamento de todas estas grandes esperanzas; quedarán inciertas si la

33 Seguin, M. S., «Les manuscrits philosophiques clandestins: une pensée en mouvement. L'exemple de La religion chrétienne analysée et de ses paratextes ", en Tangence, 81, 2006, p. 77. Diderot, D., Correspondance, en Assézat-Tourneux (ed.) Op. cit, vol. XIX. 
lengua no es fijada y transmitida a la posteridad en toda su perfección; y este objeto es el primero entre los que conviene que se ocupen con profundidad los enciclopedistas. ${ }^{34}$

Como puede notarse, el problema aquí es lingüístico pero en el fondo se trata de la comprensibilidad del legado filosófico. Mitia Rioux-Beaulne ha llamado la atención sobre un pasaje de las Observaciones sobre Hemsterbuis, en el que Diderot advierte al autor el peligro de expresarse con disimulo por temor a la censura: "Eres un ejemplo, entre muchos otros, en los que la intolerancia ha forzado la veracidad y ha vestido a la filosofía con el traje de Arlequín, de modo que la posteridad, impresionada por contradicciones cuya causa ignora, no sabrá qué decir acerca de sus verdaderas opiniones".35 El traje del Arlequín, como sabemos, es un todo confeccionado de retazos desiguales entre sí, discordantes. Diderot cree que la escritura disimulada con recursos de este tipo sólo sirve para comunicarse entre gente que comparte "el secreto". Habíamos visto ya que el mensaje cifrado era una de las características de los tratados de los libertinos eruditos. En este sentido, lo que Diderot está denunciando en el texto es algo que sólo puede ser comprendido si se tiene en cuenta que la vida del sabio apartado de la comunidad ya no forma parte de su ideal de filósofo. Unos fragmentos del artículo "PHILOSOPHE" de la Encyclopédie, escrito por Du Marsais y que Diderot retocó en puntos significativos, resultan relevantes para comprender esta nueva autorepresentación:

Nuestro filósofo no se considera exiliado de este mundo; no cree estar en un país enemigo. (...) La sociedad civil es para él, por así decirlo, una divinidad sobre la tierra; él la alaba y la honra con su honestidad, con una preocupación

34 Seguin, M. S., «Les manuscrits philosophiques clandestins : une pensée en mouvement. L'exemple de La religion chrétienne analysée et de ses paratextes », en Tangence, 81, 2006, p. 77.

34 Diderot, D., Correspondance, en Assézat-Tourneux (ed.) Op. cit, vol. XIX.

34 Diderot, D. et d'Alembert, J. (eds.), Op. Cit., Vol. V, p. 636.

35 Rioux-Beaulne, M., «Diderot face à la clandestinité : le cas de La promenade du sceptique », en La lettre clandestine, 19, 2011, p. 98. 
puntual por sus deberes y con un sincero deseo de no ser un miembro inútil o embarazoso. (...) [E]s fácil ver cuán lejos está el sabio insensible de los estoicos de la perfección de nuestro filósofo. (...) Ellos se avergonzaban de la humanidad, y él hace de ella su gloria. ${ }^{36}$

Cuando Ariste solicita el permiso para publicar el manuscrito, Cléobule reacciona con un pesimismo que contrasta con las últimas líneas de la cita:

No te reprocho por trabajar en la ilustración de los hombres; es el servicio más importante que uno puede proponerse prestarles, pero también es algo que nunca se logra. Presentar la verdad a cierta gente es, dijo uno de nuestros amigos, un día que conversaba con él bajo estas sombras, introducir un rayo de luz en un nido de lechuzas; no sirve más que para herir sus ojos y provocar sus gritos. Si los hombres fueran ignorantes por no haber aprendido nada, tal vez se los instruiría; pero su ceguera es sistemática. Ariste, no solamente tratas con gente que no sabe nada, sino con gente que no quiere saber nada. Se puede desengañar a aquél cuyo error es involuntario; pero ¿por qué lado atacar a quien está en guardia contra el sentido común? (p. 181).

El sabio parece resignado ante la posibilidad de ilustrar al pueblo, y prefiere sacar provecho de su sabiduría en soledad, o en una comunidad de iguales. Ariste se mostrará en desacuerdo con esta idea e insistirá en que el esfuerzo debe hacerse. Pero Cléobule lo advertirá con consejos de prudencia:

No esperes, por lo tanto, que tu obra sirva de mucho a los otros; pero teme que te perjudique infinitamente a ti mismo. La religión y el gobierno son temas sagrados a los cuales no se está permitido tocar. Quienes tienen el timón de la Iglesia y del Estado se verían en un gran aprieto si tuvieran que darnos una buena razón del silencio que nos imponen; pero lo más seguro es obedecer y callarse, a menos que se haya encontrado en el aire un punto fijo fuera del alcance de sus flechas, desde donde pueda anunciárseles la verdad (p.181).

36 Diderot, D. et d'Alembert, J. (eds.), Op. Cit., Vol. XII, p. 510. 
Lo que propone Cléobule a Ariste es el silencio o la clandestinidad. Si se decide por esta última, deberá asegurarse de estar fuera del alcance de los censores, pues de otro modo arriesgaría su vida. La reacción de Ariste es contundente:

Comprendo, le respondí, toda la sabiduría de tus consejos; pero sin comprometerme a seguirlos, me atreveré a preguntarte ¿por qué la religión y el gobierno son temas sobre los que se nos prohíbe escribir? Si la verdad y la justicia no pueden más que ganar con mi examen, es ridículo que se me prohíba examinar (p. 182) Impónganme el silencio sobre la religión y el gobierno y no tendré nada más para decir (p. 184).

La última línea de la cita ha generado algunas controversias entre los especialistas. A menudo se cita este pasaje como ejemplo de la manifestación de un cambio de ethos en el partido filosófico de mitad de siglo. Pero, como sostuvo Rioux-Beaulne, ${ }^{37}$ es un error interpretarlo como un indicio sociológico de una transformación en la actitud o las motivaciones de un grupo de individuos. Desde esa perspectiva, los autores de la segunda mitad de siglo sólo habrían cumplido la tarea de difundir ideas heterodoxas que ya se encontraban en los clandestinos de principios de siglo. ${ }^{38}$ Es decir, se concebiría a la segunda generación de ilustrados como meros divulgadores y se perdería de vista la reformulación, filosófica en sí misma, de la nueva autorepresentación del filósofo.

El nuevo filósofo está ansioso por expandir las luces. Ariste no cree que haya "prejuicios en los cuales [sea] importante mantener al pueblo", como sostenía Cléobule (p. 182). Es necesario hablar del gobierno y de la religión, y es necesario hacerlo claramente, sin rodeos y en voz alta. Diderot confía en el potencial de la razón crítica, quiere enseñar a desconfiar,

${ }^{37}$ Rioux-Beaulne, R., Op. cit., p. 96.

${ }^{38}$ Esta es la tesis que defiende Jonathan Israel en su Radical Enlightenment. Cfr.: Israel, J., (2001). 
contagiando a los lectores del espíritu escéptico que recorre La promenade du sceptique. Enseñar a desconfiar, pero también es preciso construir. Como sostuvo Dieckmann:

Tenemos que reconocer, en primer lugar, que el siglo XVIII francés invita a los historiadores a establecer una división. Durante la primera parte, los autores en Francia parecen estar mayormente ocupados con la liquidación del pasado. A mediados de siglo se marca un punto de cambio; todos los esfuerzos son dirigidos hacia la construcción del presente y a la colocación de los cimientos del futuro. ${ }^{39}$

Crítica, entonces, pero también construcción. Para ello, el nuevo filósofo buscará la alianza y el respaldo de las ciencias experimentales. De éstas provendrán, como vimos en los Pensamientos, los fundamentos para la elaboración de una nueva filosofía. Pero dicha tarea no puede realizarse desde el gabinete del sabio. Requiere de un ejército renovado de hombres dispuestos a interrogar directamente a la naturaleza; está naciendo la nueva Société des gens de Lettres. Una sociedad que no quiere ser invisible, que se muestra con orgullo y que se convierte en el rostro renovado de la vieja République des Lettres. La Encyclopédie, como sabemos, será su carta de presentación y en ella se combinarán todos los elementos que caracterizaron este giro de mitad de siglo. En este sentido, la tarea que cumplió Diderot en la dirección de la obra lo coloca en el centro de la escena de la nueva configuración de la filosofía del Siglo de las Luces. Los primeros escritos de Diderot permiten comprender el rol del escepticismo como actitud crítica de los ilustrados; La promenade du sceptique en particular, creemos, es un documento valioso para comprender esos cambios que se produjeron en el seno de la Ilustración.

Recibido: 9/2014. Aceptado: 11/2014

39 Dieckmann, H., Op cit., p. 53. 